\title{
Financial capacity in older adults: a growing concern for clinicians
}

$\mathrm{D}$ etermination of whether an older person is capable of managing their own financial affairs is a vexing question for health and legal professionals, as well as government agencies such as courts and tribunals. This process is often stressful for older people, and families can find that deciding when to take over is a frustrating and divisive exercise. Having family members manage an older person's assets may result in or exacerbate existing family conflict.

\section{"Financial abuse is estimated to affect $1.1 \%$ of older Australians"}

In this article, we define financial capacity and provide an overview of the assessment process, the potential impact of impaired capacity on older adults and implications for clinicians. We focus on best-practice suggestions for clinical management of questions of financial capacity.

\section{What is financial capacity?}

Financial capacity entails the ability to satisfactorily manage one's financial affairs in a manner consistent with personal self-interest and values. ${ }^{1}$ Although the terms competency and capacity are often used interchangeably in this literature, ${ }^{2}$ we will refer to capacity throughout. The capacity to appropriately manage financial affairs has both performance and judgement aspects, ${ }^{3}$ which are distinct in that older people can have limitations in one or both. For example, an older person may be capable of carrying out financial transactions such as purchasing items, but not have the judgement required to spend within their financial means. Conversely, an older adult might have the judgement to assess the relative merits of competing demands on their financial resources, but lack the technical capacity to carry out financial transactions.

Financial capacity is just one domain of capacity. Others include the capacity to consent to medical treatment, make or revoke an enduring power of attorney, participate in research, make their own will, consent to sex, marry or divorce, vote, drive and live independently (covering a broad range of abilities). Eighteen key abilities covering nine domains of financial capacity have been identified ${ }^{4}$ and these range from simple tasks, such as being able to name coins and notes, to more complex tasks, such as making and explaining investment decisions (see Box 1).

\section{Decision making and referral}

University of Queensland Brisbane, QLD

n.pachana@uq.edu.au

doi: 10.5694/mjal4.00201

\section{Summary}

- Older people with cognitive impairment and/ or dementia may be particularly vulnerable to diminished financial decision-making capacity.

- Financial capacity refers to the ability to satisfactorily manage one's financial affairs in a manner consistent with personal self-interest and values.

- Impairment of financial capacity makes the older individual vulnerable to financial exploitation, may negatively affect their family's financial situation and places strain on relationships within the family.

- Clinicians are often on the front line of responding to queries regarding decision-making capacity, and clinical evaluation options are often not well understood.

- Assessment of financial capacity should include formal objective assessment in addition to a clinical interview and gathering contextual data.

- Development of a flexible, empirically supported and clinically relevant assessment approach that spans all dimensions of financial capacity yet is simple enough to be used by non-specialist clinicians is needed.

unless proven otherwise; however, this capacity is decision specific and may fluctuate. The United Nations Convention on the Rights of Persons with Disabilities (CRPD) entered into force in May 2008 and Australia ratified the CRPD in July 2008. The CRPD promotes supported, rather than substitute, decision making. Supported decision making can, however, be problematic. Examples of this include cases where those providing the support are not motivated to do what is in the best interests of the impaired person or where the person's level of impairment is so severe that any form of decision making by the impaired person is no longer possible. Informal arrangements to cover both these situations are available and are outlined in a guide to guardianship and administration laws across Australia published by the Intellectual Disability Rights Service. ${ }^{6}$ The involvement of family and friends is important, and a referral to social work services or other allied health professionals may facilitate such informal arrangements. Formal arrangements can be made through guardianship boards or tribunals that operate in most states and territories (http://www.agac.org.au). Again, referral to such bodies can be intimidating for family (and sometimes even for institutions such as residential aged care facilities). Assistance and support with such a referral from allied health professionals, general practitioners or peak bodies such as Alzheimer's Australia and Dementia Behaviour Management Advisory Services may be invaluable. 


\begin{tabular}{|c|c|c|}
\hline Domain and task & Task description & Difficulty \\
\hline \multicolumn{3}{|l|}{1 Basic monetary skills } \\
\hline a Naming coins/currency & Identify specific coins and currency & Simple \\
\hline b Coin/currency relationships & Indicate relative monetary values of coins/currency & Simple \\
\hline c Counting coins/currency & Accurately count groups of coins and currency & Simple \\
\hline \multicolumn{3}{|l|}{2 Financial conceptual knowledge } \\
\hline a Define financial concepts & Define a variety of simple financial concepts & Complex \\
\hline b Apply financial concepts & Practical application/computation using concepts & Complex \\
\hline \multicolumn{3}{|l|}{3 Cash transactions } \\
\hline a One-item grocery purchase & Enter into simulated one-item transaction; verify change & Simple \\
\hline b Three-item grocery purchase & Enter into simulated three-item transaction; verify change & Complex \\
\hline c Change/vending machine & Obtain change for vending machine use; verify charge & Complex \\
\hline d Tipping & Understand tipping convention; calculate/identify tips & Complex \\
\hline \multicolumn{3}{|l|}{4 Chequebook management } \\
\hline a Understand chequebook & Identify and explain parts of cheque and cheque register & Simple \\
\hline b Use chequebook/register & Enter into simulated transaction; pay by cheque & Complex \\
\hline \multicolumn{3}{|l|}{5 Bank statement management } \\
\hline a Understand bank statement & Identify and explain parts of a bank statement & Complex \\
\hline b Use bank statement & Identify specific transactions on bank statement & Complex \\
\hline \multicolumn{3}{|l|}{6 Financial judgement } \\
\hline a Detect mail fraud risk & Detect and explain risks in mail fraud solicitation & Simple \\
\hline b Detect telephone fraud risk & Detect and explain risks in telephone fraud solicitation & Simple \\
\hline \multicolumn{3}{|l|}{7 Bill payment } \\
\hline a Understand bills & Explain meaning and purpose of bills & Simple \\
\hline b Prioritise bills & Identify overdue utility bill & Simple \\
\hline c Prepare bills for mailing & Prepare simulated bills, cheques, envelopes for mailing & Complex \\
\hline 8 Knowledge of personal assets/estate arrangements ${ }^{\dagger}$ & Indicate asset ownership, estate arrangements & Simple \\
\hline 9 Investment decision making & Understand options; determine returns; make decision & Complex \\
\hline Overall financial capacity & Overall functioning across tasks and domains & Complex \\
\hline
\end{tabular}

\section{What are the potential impacts on older} adults?

Impaired financial capacity renders an individual vulnerable to financial exploitation through actions such as undue influence and consumer fraud. Financial abuse is estimated to affect $1.1 \%$ of older Australians, ${ }^{7}$ and was found to be the most common form of elder abuse in a Western Australian study, particularly for older women and very old people. ${ }^{8}$ Undue influence describes a situation in which an individual is able to convince another to act in a way contrary to their will. Such influence might manifest in situations where an older person is financially capable but the family or other caregivers decide to manage the older person's finances based on their own interests. Furthermore, consumer fraud is estimated to affect $5 \%$ of older Australians. ${ }^{9}$ Examples of such schemes often include taking advantage of cognitive decline in a vulnerable older person - as when a person purporting to be a tradesman comes to the door demanding payment for services supposedly carried out at an earlier time. Older adults who are more socially isolated or who are more dependent on paid external services in order to continue living in the community may be more vulnerable to such exploitation.

Given that older people's share of total wealth has increased over the past two decades and is likely to continue to do $\mathrm{so}^{10}$ the problem of financial capacity will become more pressing, and it is likely that more questions of capacity will present in primary and community health care settings.

\section{Who is more at risk?}

Recently there has been a focus on the clinical aspects of financial capacity, which broadly span cognitive, affective, instrumental and social capacity functioning. ${ }^{2}$ Older people with neurodegenerative disorders such as Alzheimer disease, Parkinson disease, frontotemporal dementia and mild cognitive impairment appear particularly vulnerable to diminishing financial capacity. ${ }^{3}$ How such changes manifest themselves, from a lifespan perspective, might be conceptualised ${ }^{11}$ as amounting to relatively minimal changes in financial capacity with normal ageing, particularly if older people have good 
social and instrumental support from family and friends. However, people with mild cognitive impairment may have increasing difficulty with more complex financial skills including bank statement management, bill payments and financial judgement, ${ }^{4}$ and it is important for families and health professionals to be mindful of reports or observations of such decline. Ideally, early intervention would allow for smoother transfer of financial responsibilities and perhaps avoidance of distress or embarrassment on the part of the person with declining financial skills.

People with mild Alzheimer disease have been reported to have impairments in both simple and complex financial skills, with rapid decline in a 1-year period. ${ }^{5}$ More global impairment of financial skills with probable financial incapacity has been reported in most people with moderate Alzheimer disease,; ${ }^{12}$ and complete lack of financial capacity in severe Alzheimer disease. ${ }^{11}$ Over time and with increasing severity of dementia, older adults may show declining interest and engagement in their financial affairs, as well as reduced concerns about the consequences of their inaction. Such a situation may continue without family members being aware that anything is amiss. Sorting out financial concerns in cases of advanced dementia, particularly in the context of familial discord, can be challenging for health care professionals.

\section{How to assess financial capacity}

There is currently no universal standard for evaluating financial capacity. Overreliance on clinical judgement or non-specific assessment tools (such as the mini-mental state examination ${ }^{13}$ ) for determining specific aspects of capacity, such as the ability to make a will and distribute assets or to determine the presence of undue influence, is worrying. Failure to include specific objective measures of financial capacity as well as emotional and cognitive functioning may result in overreliance on clinical impressions rather than objective data, and may be less useful in a legal context.

A review of clinical assessment approaches to financial capacity in older adults found that current methods were based around a clinical interview, neuropsychological assessment and performance-based assessments. ${ }^{2}$ The authors stressed the need for a multipronged evaluation. The extant literature suggests that cognitive domains relevant to capacity assessment in Alzheimer disease include conceptualisation, expressive language, numeracy skills, semantic memory, verbal recall, executive function and receptive language..$^{14}$ However, all relevant cognitive domains are often not systematically tested, or may be overassessed..$^{15}$ Important contextual and social variables that inform interpretation of objective data ${ }^{16}$ and may be directly tied to the potential for financial abuse $\mathrm{e}^{17}$ are often ignored. Moreover, reduced insight in patients about their own limitations and abilities, as well as the presence of psychiatric conditions such as depression and anxiety, can also lead to errors in judgement by patients with cognitive decline. Abilities such as insight are only infrequently examined by clinicians in the course of

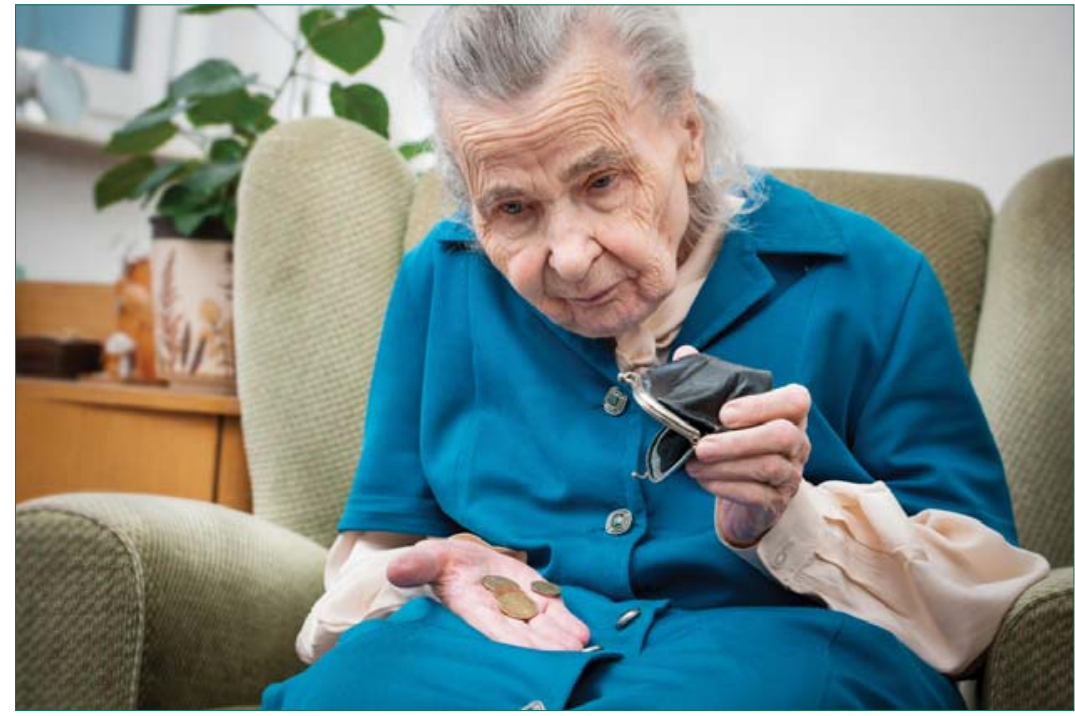

assessing financial capacity. Assessment of a person's ability to understand the facts and choices related to their decisions, to distinguish between alternatives and weigh up consequences, and to make an informed choice and communicate their decision should also be made.

Unfortunately, the research literature related to financial capacity has been difficult to translate into sound clinical practice in health care settings. Capacity assessments at times rely almost completely on clinical judgement, which is not evidence-based and which may be vulnerable to bias. ${ }^{18}$ Comparability and consistency between approaches, even in a single case, may be lacking. ${ }^{19}$ Approaches to determining capacity have rarely been empirically validated with respect to their real-world reliability and utility. ${ }^{20}$ Part of the difficulty has been establishing a credible gold standard. ${ }^{15}$

\section{What does this mean for clinicians working with older people?}

Primary care providers such as GPs and community nurses are often the first to encounter older people with diminishing financial capacity, ${ }_{1}^{11}$ and they have an important role to play in acting on their concerns; for example, by discussing them with the family or referring

\section{A brief list of instruments available for assessing financial capacity, decision making and vulnerability}

Addenbrooke's Cognitive Examination - III21

Informant Questionnaire on Cognitive Decline in the Elderly 22

Semi-Structured Clinical Interview for Financial Capacity ${ }^{12}$

Financial Competence Assessment Inventory ${ }^{23}$

Geriatric Depression Scale 24

Geriatric Anxiety Inventory ${ }^{25}$

Instrumental Activities of Daily Living Scale for elderly people ${ }^{26}$ 
the patient for more formal capacity assessment. Five different roles that clinicians may choose to adopt have been suggested: ${ }^{11}$ educating patients and families about the need for advance financial planning; recognising signs of possible impaired financial capacity; assessing financial impairment, financial abuse or both; recommending interventions to help patients maintain financial independence; and making timely and appropriate medical and legal referrals. This approach seems relevant to all clinicians working with older people. Ideally, all three of the suggested assessments - clinical interview, neuropsychiatry assessment and performance-based tests - would be conducted to assess capacity.

A comprehensive clinical interview is vital to directly assessing financial capacity with respect to a patient's physical and emotional health. Objective assessment of cognitive function and potential psychiatric disorders, such as depression, anxiety, and psychosis and related symptoms such as delusions, are important and should use instruments that have been appropriately normed and, wherever possible, developed for geriatric populations. Performance-based assessment of financial capacity and decision making, as well as an assessment of a person's vulnerability to undue influence and exploitation, are also important. ${ }^{2} \mathrm{~A}$ brief list of relevant instruments to consider appears in Box 2; this list is indicative rather than exhaustive.

\section{Conclusions}

Financial capacity is emerging as an important concern related to older people and those involved in their care. Assessment of financial capacity should include formal objective assessment in addition to a clinical interview and gathering of contextual data. There is no one instrument that can be used in isolation; use of multiple sources of data, objective performance-based tests, neuropsychiatric assessments and self-report clinical interview data is recommended. The decisions that result from an assessment of capacity can have far-reaching consequences. In order to better meet the needs of patients, their families and their carers, as well as clinicians involved in such assessments, standards and guidelines for the assessment of capacity are needed.

Acknowledgements: This project was funded by a National Health and Medical Research Council dementia grant (511119).

Competing interests: No relevant disclosures.

Provenance: Not commissioned; externally peer reviewed. 
1 Marson DC, Hebert T. Financial capacity. In: Cutler BL, editor. Encyclopedia of psychology and the law, vol 1. Thousand Oaks, Ca: Sage Publications, 2008: 313-316.

2 Pinsker DM, Pachana NA, Wilson J, et al. Financial capacity in older adults: a review of clinical assessment approaches and considerations. Clin Gerontol 2010; 33: 332-346.

3 Marson DC. Clinical and ethical aspects of financial capacity in dementia: a commentary. Am J Geriatr Psychiatry 2013; 21: 382-390.

4 Griffith HR, Belue K, Sicola A, et al. Impaired financial abilities in mild cognitive impairment: a direct assessment approach. Neurology 2003; 60: 449-457.

5 Martin RC, Griffith HR, Belue K, et al. Declining financial capacity in patients with mild Alzheimer's disease: a one-year longitudinal study. Am J Geriatr Psychiatry 2008; 16: 209-219.

6 Fogarty B. Guardianship and administration laws across Australia. Intellectual Disability Rights Service, 2009. Revised by Morris M, 2012. http://www.idrs.org.au/pdf/Guardianship_ and_administration_laws_across_Australia_by_Ben_Fogarty. pdf (accessed May 2014).

7 Kurrle S, Naughtin G. An overview of elder abuse and neglect in Australia. J Elder Abuse Negl 2008; 20: 108-125.

8 Boldy D, Horner B, Crouchley K, Davey M. Addressing elder abuse: Western Australian case study. Australas J Ageing 2005; 24: 3-8.

9 Carcach C, Graycar A, Muscat G. The victimisation of older Australians. Trends and issues in crime and criminal justice series. Canberra: Australian Institute of Criminology, 2001.

10 Kelly S, Harding A. Funding the retirement of baby boomers. Agenda 2004; 11: 99-112.

11 Widera E, Steenpass V, Marson D, Sudore R. Finances in the older patient with cognitive impairment: "He didn't want me to take over”. JAMA 2011; 305: 698-706.

12 Marson DC, Martin RC, Wadley V, et al. Clinical interview assessment of financial capacity in older adults with mild cognitive impairment and Alzheimer's disease. J Am Geriatr Soc 2009; 57: 806-814.

13 Folstein MF, Folstein SE, McHugh PR. "Mini-mental state". A practical method for grading the cognitive state of patients for the clinician. J Psychiatr Res 1975; 12: 189-198.
14 Marson DC, Chatterjee A, Ingram KK, Harrell LE. Toward a neurologic model of competency: cognitive predictors of capacity to consent in Alzheimer's disease using three different legal standards. Neurology 1996; 46: 666-672.

15 Sullivan K. Neuropsychological assessment of mental capacity. Neuropsychol Rev 2004; 14: 131-142.

16 Tilse C, Setterlund D, Wilson J, et al. Minding the money: a growing responsibility for informal carers. Ageing Soc 2005; 25: 215-227.

17 Setterlund D, Wilson J, Tilse C, Robbinson G. Financial abuse within families: views from family members and professionals. Symposium on assets, ageing and abuse. 8th Australian Institute of Family Studies Conference; 2003 Feb 12-14; Melbourne, Australia.

18 Moye J. Assessment of competency and decision making capacity. In: Lichtenberg PA, editor. Handbook of assessment in clinical gerontology. New York: Wiley, 1999: 488-528.

19 Marson DC, McInturff B, Hawkins L, et al. Consistency of physician judgments of capacity to consent in mild Alzheimer's disease. J Am Geriatr Soc 1997; 45: 453-457.

20 Marson DC, Schmitt FA, Ingram KK, Harrell LE. Determining the competency of Alzheimer patients to consent to treatment and research. Alzheimer Dis Assoc Disord 1994; 8 Suppl 4: 5-18.

21 Neuroscience Research Australia. Addenbrooke's Cognitive Examination-III (ACE-III). http://www.neura.edu.au/frontier/ research/test-downloads (accessed Nov 2013).

22 Jorm AF. A short form of the Informant Questionnaire on Cognitive Decline in the Elderly (IQCODE): development and cross-validation. Psychol Med 1994; 24: 145-153.

23 Kershaw MM, Webber LS. Assessment of financial competence. Psychiatry, Psychol Law 2008; 15: 40-55.

24 Yesavage JA, Brink TL, Rose TL, et al. Development and validation of a geriatric depression screening scale: a preliminary report. J Psychiatr Res 1982-1983; 17: 37-49.

25 Pachana NA, Byrne GJ, Siddle H, et al. Development and validation of the Geriatric Anxiety Inventory. Int Psychogeriatr 2007; 19: 103-114.

26 Mathuranath PS, George A, Cherian PJ, et al. Instrumental activities of daily living scale for dementia screening in elderly people. Int Psychogeriatr 2005; 17: 461-474. 